\title{
ATIVIDADE DOCENTE EM CONTEXTO INCLUSIVO: UM OLHAR SOBRE O ENSINO DE MATEMÁTICA
}

\author{
C. L. A. ROLIM, * S. M. A. LIMA E R. LAGARES \\ Universidade Federal do Tocantins - UFT \\ carmem.rolim@uft.edu.br ${ }^{*}$
}

Submetido 30/09/2015 - Aceito 13/04/2017

DOI: $10.15628 /$ holos.2017.3461

\section{RESUMO}

O presente estudo objetivou investigar a atividade docente no contexto das especificidades educacionais, considerando a proposta da educação especial na perspectiva inclusiva; especificamente, o processo de ensino-aprendizagem de matemática, realizado em salas de aula comum. Considerando a abordagem qualitativa e dando voz ao professor, adentra-se ao espaço escolar por meio de políticas voltadas à educação para as pessoas com necessidades educacionais especiais, como também, consideram-se as ações realizadas pela prática docente. As análises possibilitam afirmar que a educação inclusiva se efetivou, principalmente, pelo acesso dos alunos com necessidades especiais ao ambiente escolar, porém, considerando o processo de ensino-aprendizagem de matemática suas ações mostram-se insuficientes; tanto no âmbito da educação básica quanto no ensino superior. Realidade que requer políticas que oportunizem a articulação entre os profissionais de ensino, os espaços pedagógicos e a sociedade, e, diferentemente de um processo excludente, que acentua e condena o erro, propicie o contexto no qual a atividade docente possa avançar em possibilidades, oportunizando, a todos, o direito de pertencimento a comunidade escolar e a sociedade.

PALAVRAS-CHAVE: Prática docente inclusiva, formação de professores, educação matemática.

\section{TEACHER ACTIVITY IN INCLUSIVE CONTEXT: A LOOK AT MATH EDUCATION}

\section{ABSTRACT}

This study aimed to investigate the teacher activity in the context of the educational specifics, considering the proposal of special education in the inclusive perspective, specifically, the process of teaching and learning mathematics, held in common classrooms. Considering the qualitative approach and giving voice to the teacher, we enter the school environment by means of policies to education for people with special educational needs, but also consider the actions that take place through the teaching practice. The analysis reveals that inclusive education policy was effective,
\end{abstract}

especially in ensuring access of students, however, considering the mathematics teaching-learning process their actions prove to be insufficient; both in basic education and in higher education.

Reality which requires policies that make possible the joint between education professionals, pedagogical spaces and society, and unlike an exclusionary process that accentuates and condemns the error, propitiates the context in which the teaching activity can advance possibilities, providing at all, the right of belonging to the school community as well as society.

KEYWORDS: Inclusive teaching practice, teacher training, math education. 


\section{APRESENTAÇÃO}

Nas últimas décadas, embora que timidamente, a educação brasileira tem registrado avanços no que se refere ao reconhecimento dos direitos das pessoas com necessidades especiais.

Contexto no qual se delineiam políticas educacionais voltadas a garantir o desenvolvimento do aluno com especificidades. Esse cenário propõe novas questões exigindo do docente e do contexto escolar a reelaboração de ações didáticas desenvolvidas nos diversos componentes curriculares, dentre os quais, destacamos a disciplina de matemática.

A delimitação pela área de matemática surge por sua contribuição para o desenvolvimento do raciocínio lógico, espacial e numérico, mas também, por sua relevância social, nas palavras de Rolim (2014, p. 95), "não dominar conteúdos matemáticos, cria em nossa cultura movimentos que classificam sujeitos, acabando por influenciar não apenas as relações que ocorrem em sala de aula, mas causando fragmentações que se perpetuam na sociedade".

Considerar o conhecimento matemático como um bem cultural, historicamente construído é reconhecer que, como tal, se institui em um direito inalienável do sujeito. Proposição que questiona o processo de inclusão, instigando a conhecer a prática docente em salas de aula do ensino regular que acomodam alunos com especificidades e a refletir sobre os processos formativos que fundamentam o fazer pedagógico.

Nessa busca, seguimos a abordagem qualitativa, por meio da pesquisa participante, tendo como recursos a observação e a entrevista; e, como técnica de registro o diário de campo e a gravação audiovisual. A análise dos dados considera as orientações de Triviños (1990) e Góes (2000), buscando nas minúcias o confronto de ideias, movimento que oportuniza a formação de novas questões e, portanto, novas buscas; em nosso caso reflexões acerca das práticas e dos processos formativos. Pressupostos que orientaram o estudo, desenvolvido entre os anos de 2012 e 2014, em três escolas públicas da rede municipal de ensino da cidade de Palmas no estado do Tocantins.

Os sujeitos do estudo foram delimitados aos professores que ensinam matemática em salas de aula comum do 60 ao 90 ano do ensino fundamental, em contextos inclusivos. Por se tratar de uma pesquisa envolvendo seres humanos, e, concordando com Bogdan e Biklen (1994), que discorrem sobre a ética em investigações científicas, o estudo foi submetido e aprovado pelo comitê de ética, sendo resguardada a identidade dos sujeitos e a identificação das escolas, para tanto, utilizamos nomes fictícios.

Dessa forma, a investigação foi organizada em dois momentos, o primeiro versa sobre as perspectivas legais e as ações voltadas à educação para as pessoas com necessidades educacionais especiais, provenientes de alguma deficiência, considerando a proposta educacional inclusiva. O segundo momento direciona o olhar para o professor, focalizando o processo de ensino-aprendizagem ante a atividade docente realizado no contexto da sala de aula comum. 


\section{PERCURSO INCLUSIVO: PERSPECTIVAS LEGAIS}

O caminho que objetiva garantir o direito à educação para as pessoas com necessidades especiais é longo, adentrou em diferentes contextos, perpassou da superação da segregação à busca de inclusão. Um caminhar que ressalta a negação de direitos, marcado pelo isolamento e o estigma da diferença. Para a pessoa com necessidade especial foi negado por muitos anos, não apenas, o direito a educação, mas também o convívio social e o exercício pleno de sua cidadania.

Historicamente, no cenário brasileiro, o atendimento às pessoas com alguma deficiência era exclusivamente clínico, situação que mais tarde ampliou-se para o pedagógico, porém, manteve o processo de isolamento social. Dessa forma, o atendimento era localizado em hospitais ou escolas especiais, perpetuando o processo discriminatório (Januzzi, 2006).

Perspectiva na qual, foram criadas instituições no período imperial de caráter asilar, que acolhiam de forma caritativa crianças e adultos, muitas vezes, abandonados por suas famílias e discriminados pela sociedade. Processo que começou a mudar quando;

Em 1948, com a Declaração Universal dos Direitos Humanos, a Organização das Nações Unidas proclama que 'Todos os homens nascem livres e iguais em dignidade e direitos', e, encaminha pactos e convenções internacionais para eliminação de formas de discriminação e violência [...]. A dedicação a grupos vulneráveis fez-se necessária para que aqueles direitos universais de natureza individual e social encontrassem instrumentos jurídicos hábeis para torná-los eficazes. Defender as minorias significa assegurar direitos humanos básicos: a livre expressão, o direito de ir e vir, o trabalho, a educação, a seguridade social, a cultura, o lazer, o esporte, a moradia - que são direitos de todos. Esses direitos justificam os movimentos sociais que emergem em nossa sociedade e não poderia ser diferente no âmbito das associações voltadas às pessoas com deficiência (Cabral Filho, Ferreira, 2013, p. 99).

Nesse caminhar, a família e a sociedade são chamadas como partícipes do processo, visando o reconhecimento da pessoa enquanto cidadã livre e digna, devendo atuar de maneira mais efetiva contra a discriminação e a qualquer forma de segregação ou violência.

Movimento que impulsiona, já no período republicano, a fundação de instituições como, a Sociedade Pestalozzi no Brasil e Associação de Pais e Amigos dos Excepcionais (APAE), entretanto, diferentemente da conscientização da educação como direito, em que se pauta a proposta inclusiva, o assistencialismo compunha a centralidade dos atendimentos.

Segundo Lanna Júnior (2010), esses movimentos atuaram para a conscientização social, culminando com o reconhecimento dos direitos das pessoas com deficiência, explicitados pela Lei no 4.024, de 1961 (Brasil, 1961). Porém, o avanço do processo educacional teve um entrave, ao vincular o atendimento inclusivo ao termo "preferencialmente", e, dessa forma, a efetivação de ações voltadas à equidade social foi adiada.

Somente com intensas mobilizações, o país começa a mudar o rumo da discussão e elabora um contingente de leis, muitas dessas, impetradas pela atuação das próprias pessoas com deficiências que, articuladas, lutam em prol de seus direitos e asseguram-nos na Constituição Federal de 1988. (Brasil, 1988). Um processo que procura suprimir o caráter assistencialista da educação em busca da equidade entre as pessoas, reconhecendo o direito de 
todos ao processo de ensino-aprendizagem, ideia que se contrapõe a opressão de uma sociedade excludente.

Essa fase tem como desfecho a elaboração de inúmeros documentos, entre os quais destacamos o artigo 59, inciso III da LDB, Lei no 9.394 de 1996, que trata da formação dos profissionais para o atendimento educacional com ênfase na integração dos educandos. Orienta que os sistemas de ensino devem assegurar, "professores com especialização adequada em nível médio ou superior, para atendimento especializado, bem como professores do ensino regular capacitados para a integração desses educandos nas classes comuns." (Brasil, 1996, p. 44). Caberia aos professores do ensino regular apenas zelar pela integração dos educandos com necessidades educacionais especiais? Responder a essa questão passa pelo entendimento do conceito de integração.

Para Bruno (2006), o conceito de integrar surge, inicialmente, relacionado ao processo de normalizar, estando conexo ao processo de adequar.

O conceito de integração tem origem no princípio ideológico e filosófico da normalização, criado na Dinamarca [...], e, amplamente adotado na Suécia, em 1969. Esse conceito defendia, para as crianças com deficiências, modos de vida e condições iguais ou parecidas com as dos demais membros da sociedade. A ideia da normalização, como foi proposta, subentendia não tornar o indivíduo "normal", mas torná-lo capaz de participar da corrente natural da vida, inclusive da escola (Bruno, 2006, p.13).

Nas palavras de Lima (2014), integrar o sujeito com necessidade especial ao contexto social, direciona a adaptação das pessoas às normas ditadas pela classe hegemônica.

A integração favorece aqueles providos com maior capacidade adaptativa e considerados aptos a se adequarem às normas sociais. $O$ foco integrativo restringe a ação colaborativa e a responsabilidade da sociedade, uma vez que o não aprendizado ou a não adequação do sujeito justifica-se na inabilidade de este se adaptar e desenvolver atividades profissionais ou acadêmicas postas aos 'ditos normais' (Lima, 2014, p. 29).

Segundo Lanna Júnior (2010) e Januzzi (2006), essa perspectiva coloca o aluno em situação de adaptação à proposta de ensino, um retrocesso às proposições educacionais igualitárias.

A relevância, porém, insuficiência da ideia de integração é pontuada por Crochik et al. (2006), que associa o conceito de integração ao conceito inclusão no contexto da proposta da educação especial. Segundo os autores, a importância de ambos os conceitos está na busca pela igualdade para grupos minoritários que se encontram em caráter de exclusão.

Ainda que julguemos importante tal distinção, concordamos que ela não deva levar à divisão de esforços na luta pela inserção de crianças com necessidades educativas especiais em salas de aula regulares: é melhor, a nosso ver, a educação integrada do que a segregada, ainda que a educação inclusiva indique ser a mais adequada (Crochik et al., 2006, p. 57).

Proposição que indica, ainda, a necessidade de promover uma educação que ultrapasse os ajustes de um sistema fragmentado, uma vez que; 
Sem alterar o delineamento do currículo e as metodologias, sem estabelecer esquemas de suporte efetivo ao professor, a escola não responde ao compromisso com o desenvolvimento e a aprendizagem dos indivíduos diferentes (Góes, 2004, p.74).

Dessa forma, entendemos que a proposta da educação especial na perspectiva inclusiva exige reestruturação tanto, nos aspectos físicos como nas ações pedagógicas da escola, a fim de encontrar respostas às demandas dos educandos com especificidades. Modificações que reconhecem a diversidade, mas em sentido oposto ao da classificação e da segregação, impulsionam o desenvolvimento das potencialidades do educando. Nesse sentido, existe o imperativo de transformar o contexto escolar e oportunizar processos formativos aos professores no intuito de garantir o direito do educando de ser aluno entre alunos.

Essa preocupação foi o ponto central das discussões realizadas na III Conferência Nacional dos Direitos das Pessoas com Deficiência, em 2012. Destacamos a proposta número 25, que indica às instituições educacionais a necessidade de "promover ações que garantam por meio de legislação, carga horária mínima de 120 horas anuais para capacitação e formação continuada em serviço na área de educação especial, para todos os profissionais da unidade escolar." (Brasil, 2013, p. 34).

A proposta vem ao encontro dos anseios de professores e demais profissionais da educação que julgam desafiador o atual contexto, uma vez que, grande parte dos docentes em atividade não participou de processos formativos para o desenvolvimento da atividade pedagógica em situações de especificidades (Januzzi, 2006).

Nesse cenário, olhar o contexto da sala de aula e a formação do professor tornou-se imperativo, indicando a necessidade de adentrar a atividade docente em situação de especificidade.

\section{ATIVIDADE DOCENTE: SUJEITOS, ESPAÇOS E CONTEXTOS}

Investigar o professor no contexto inclusivo envolve os significados atribuídos às atividades docentes, um processo que abrange a formação do professor, os espaços educativos, as metodologias de ensino considerando as especificidades: do conteúdo curricular e as necessidades especiais do educando, porém, sem desvincular-se da educação geral. Contexto que necessita alinhar o processo de ensino-aprendizagem desenvolvido tanto na educação especial como na educação geral. O desafio consiste em "encontrar tal sistema, que permita ligar organicamente a pedagogia especial com a pedagogia normal." (Vygotsky, 1997, p. 59).

Dessa forma, a atividade docente não se constitui independentemente do conteúdo de sua área de conhecimento e do contexto educacional, ela se desenvolve em uma estrutura sociocultural, que considera professores e alunos, mas também, o seu entorno, isto é, os diferentes setores de apoio ao processo de ensino-aprendizagem e os espaços onde a docência se efetiva (Leontiev, 1978).

Com esse olhar nos aproximamos dos professores que ensinam matemática em contextos inclusivos, em salas de aula comum do 6으 ao 9으 ano do ensino fundamental, de três escolas públicas da rede municipal da cidade de Palmas no estado do Tocantins. 
O contato com os docentes e seu contexto de trabalho possibilitou entendimentos quanto ao espaço escolar e as dificuldades vivenciadas pelos professores para o ensino de matemática. As escolas foram denominadas de forma fictícia, sendo a primeira indicada como Olavo Bilac, à segunda Cecília Meireles e a terceira Castro Alves.

\subsection{Atividade docente: contexto colaborativo}

$\mathrm{Na}$ observação dos espaços em que a atividade docente se desenvolve encontramos situações diferenciadas, porém o contexto colaborativo é evidenciado pelos docentes entrevistados, nas três escolas pesquisadas.

A escola Olavo Bilac, possui docentes regentes de matemática que atuam em contextos inclusivos, professores da sala de recursos e uma professora auxiliar. Tanto nas observações como na fala dos professores encontramos indicações de processos colaborativos entre os setores da escola e os docentes.

\footnotetext{
Contamos com uma professora auxiliar [...], ela fica por nossa conta para ajudar. Daí ela vai de uma sala a outra. Pesquisa atividades e ajuda a organizar os cadernos, até porque o tempo de planejamento é curto e a organização de atividades para os alunos especiais requer outros conhecimentos que não dispomos (Neves, 2013, entrevista individual).
}

Situação que evidencia a necessária articulação entre o professor do atendimento educacional especializado e os professores regentes da classe comum, pois a relação auxilia a ação didática para a inclusão, compromisso que demanda esforços conjuntos da comunidade escolar. A fala revela, ainda, a quantidade insuficiente de profissionais para o apoio educacional especializado. Pois, apesar da presença do professor auxiliar, ele é único na escola, exigindo seu desdobramento para o atendimento nas diversas salas de aula que possuem alunos com especificidades.

Na segunda instituição, a escola Cecília Meireles, a relação entre os setores não foi considerada de forma positiva pelos professores. Pois, apesar de as observações indicarem que o docente procura planejar e envolver os alunos com necessidades educacionais especiais nas atividades propostas, à fragilidade da articulação entre os professores responsáveis pelo contexto educativo e a quantidade insuficiente de profissionais habilitados é evidenciada.

Aqui não há uma pessoa para auxiliar ou dividir essa missão com o professor. O apoio que nós temos é da professora da sala de recursos, 'ela acompanha os alunos no contra turno', mas na sala de aula não temos nenhum apoio (Costa, 2013, entrevista individual).

As observações realizadas no decorrer da pesquisa revelaram, ainda, que tal situação traz reflexos para os educandos, pois a ação docente acaba sendo direcionada, principalmente, para os alunos que apresentam certa potencialidade ou, ainda, que o docente julga capaz de aprender. Aos demais é legado, ainda que inconscientemente; certo distanciamento e isolamento.

Nesse espaço educativo, o aluno é deixado livre para fazer outras tarefas, pintar, rabiscar ou até responder de forma arbitrária o exercício proposto ao restante da turma. Realidade na qual o professor demonstra preocupação com o processo de aprendizagem dos alunos com 
necessidades especiais, contudo, sem o acompanhamento adequado o docente acaba por restringir o processo de aprendizagem apenas ao convívio social.

Situação que revela semelhanças com a escola Olavo Bilac, porém na escola Cecília Meireles o docente destaca a falta de apoio de forma mais enfática, indicando a existência, porém insuficiência do atendimento no contra turno.

$\mathrm{Na}$ terceira instituição, a escola Castro Alves, a falta de apoio entre os espaços pedagógicos foi marcado como ponto negativo pelos docentes e a prática pedagógica se apresentou um tanto diferente das outras duas escolas.

\footnotetext{
Na verdade, não conto com nenhum apoio. O que se faz é um trabalho paralelo na sala de recursos multifuncionais. A professora da sala de recursos repassa algumas informações sobre o aluno e a partir daí o trabalho é nosso. Eu tenho um aluno no sexto ano e tenho que adaptar sozinho, as atividades elementares e desenvolver os exercícios, como se estivesse alfabetizando-o (Pires, 2013, entrevista individual).
}

Um fazer docente que, na desconexão das ações dos setores educacionais, colabora para a fragmentação do processo de ensino. As sessões de observação indicaram também, que a falta de apoio, entre os espaços pedagógicos, coloca o professor em situação de isolamento, contribuindo para que o processo inclusivo seja visto, pelo docente, como um peso e acabe por comprometer a ação didática.

Os contextos das escolas, embora diferentes, revelam que as atividades pedagógicas são construções colaborativas, então, precisam do compromisso da sociedade em acompanhar, estruturar e viabilizar seu processo de desenvolvimento, a fim de possibilitar a realização plena da atividade educacional.

\subsection{Atividade docente para o ensino de matemática}

As observações indicaram, ainda, que as atividades de ensino de matemática no contexto da sala de aula comum foram marcadas por metodologias que se assemelham para todos os alunos, independentemente do conteúdo abordado ou da especificidade do educando. Dessa forma, ao igualar as metodologias de ensino e desconsiderar as especificidades do aluno, as possibilidades do aprendiz são desprezadas, desse modo, acaba-se por condenar a criança a viver a margem do processo educativo (Vygotsky, 1997).

Porém essa dificuldade não passa despercebida pelos docentes e se transforma em angústia diante do reconhecimento pela inabilidade com o processo de ensino.

Quando me deparei com essa situação, foi um grande desafio e ao mesmo tempo uma grande preocupação. Nós temos uma sala de aula com quarenta alunos durante 50 minutos para ministrar a aula e dar assistência a todos, sendo que precisamos dar uma assistência maior ao aluno com necessidades educacionais especiais e nós não temos condição [balança a cabeça], [...] mas eles aprendem uns com mais dificuldade, outros com menos facilidade (Costa, 2013, entrevista individual).

Eu tenho também dificuldades em relação a isso [ensinar conteúdos matemáticos em contexto inclusivo], porque não tive uma formação voltada para atender a esses alunos na escola; às vezes tenho dificuldades em certos conteúdos a fim de lhes repassar. Não é nada fácil (Martins, 2013, entrevista individual). 
Eu sinto muitas dificuldades, receio, fico pensando será que estou fazendo certo, será que não estou, será que é assim mesmo? Como será que tem de ser? Vou falar a verdade, a gente não tem formação específica para atuar nessa área então fica a dúvida, mas procuro fazer o melhor. Para que eles aprendam utilizo materiais diferentes, mesmo sem certeza, busco. Pois, a minha satisfação está na aprendizagem do aluno (Neves, 2013, entrevista individual).

Essa questão de trabalhar com alunos especiais, no meu entender, deixa muito a desejar; por exemplo, a questão do aluno 'mudo', não estudei Libras, não fui preparado para isso, a nossa formação não nos preparou para lidar com essa situação, assim como não sei Braille para trabalhar com alunos cegos, então é difícil (Pires, 2013, entrevista individual).

As falas dos docentes que ensinam matemática em salas de aula comum denunciam uma busca por vezes solitária envolvendo o contexto inclusivo e explicitando fragilidades que residem no processo de formação do professor, evidenciando a necessidade de investimentos na formação tanto na inicial como na continuada, bem como na estruturação do contexto educacional.

São relatos que expressam a conquista pela presença da diversidade no contexto da classe comum, mas indicam também, dificuldades e angústias pela estrutura educacional deficitária, como pela inabilidade com a atividade docente, por vezes, relacionada à formação. Situação que confirma a necessidade de políticas que efetivem de fato, as conquistas que, muitas vezes, já foram instituídas legalmente como direito.

\section{CONSIDERAÇÕES FINAIS}

Buscando as especificidades de ações didáticas que se efetivam no contexto escolar e tencionam a inclusão, adentramos em um sistema educacional municipal com estruturas físicas e orientações pedagógicas que se assemelham, porém tanto a prática docente como a estrutura de apoio se mostram de forma diferente nas três escolas investigadas. Situação que traz indícios de um sistema fragilizado e instiga a reflexão sobre a realidade da educação brasileira.

Retomando o processo histórico, observamos que conquistas foram obtidas no contexto da educação especial, principalmente, no que se refere à matrícula dos alunos. Considerando a perspectiva legal, a educação inclusiva está amparada pela legislação que dispõem sobre a formação, reestruturação dos tempos e espaços de ensino, bem como recursos didáticos, no entanto, para a efetivação da educação inclusiva os ajustes são urgentes.

Trazendo a atividade docente que busca a inclusão, na voz do professor, observamos que pontuações positivas e negativas se inter-relacionam. O significado negativo está relacionado, principalmente, com a inabilidade para trabalhar com o educando, bem como o descompromisso da sociedade explicitado pela falta de apoio, seja para o aprimoramento profissional do professor como para o desenvolvimento de estruturas educacionais que favoreçam o desenvolvimento das potencialidades do educando. 
As experiências positivas, ainda que submersas nos discursos, estão relacionadas aos avanços da aprendizagem dos alunos e a existência de alguns processos colaborativos que, por vezes, são vivenciados no contexto escolar.

Independentemente da postura dos professores diante dos desafios da educação inclusiva é possível constatar o esforço dos docentes no cumprimento do processo de ensino. Porém, fica explícito que a atividade de ensino é fortemente influenciada pela formação e pelo contexto escolar. Processos que extrapolam os muros das escolas e evidenciam a responsabilidade da sociedade. Retomando Vygotsky (1997) observamos que, educar no contexto das especificidades é construção inclusiva que se efetiva somente quando significada socialmente.

Dessa forma, destacamos a relevância da articulação entre os profissionais de ensino, os espaços pedagógicos e a sociedade, ou seja, é imprescindível que o contexto sociocultural no qual se situa a escola e seus alunos, seja inclusivo.

Consideramos, então, que a atividade docente que busca a inclusão, investe em possibilidades. Ela não se constitui de forma isolada, é social e repleta de intencionalidades. Situação que exige políticas educativas que avancem o processo de ensino-aprendizagem, principalmente que coloque no passado as ações que perpetuavam a desigualdade e a segregação.

Nesse sentido, a atividade docente de matemática que busca a inclusão, não é processo solitário e restrito aos limites da sala de aula, é construção que perpassa o conceito dos direitos de cidadania e, dessa forma, requer ações políticas que invistam nas potencialidades dos professores e dos educandos, e, diferentemente de um processo excludente, que acentua e condena o erro, avance em possibilidades.

\section{REFERÊNCIAS}

Bogdan, R., Biklen, S. (1994). Investigação qualitativa em educação. Porto: Porto Editora.

Brasil. (1961). Lei no 4.024 de 20 de dezembro de 1961. Fixa as Diretrizes e Bases da Educação Nacional. Brasília: Diário Oficial [da República Federativa do Brasil].

Brasil. (1988). Constituição da República Federativa do Brasil de 1988. Brasília: Câmara dos Deputados, Edições Câmara.

Brasil. (1996). Lei 9.394 de dezembro de 1996. Estabelece as diretrizes e bases da educação nacional. Brasília: Diário Oficial [da República Federativa do Brasil].

Brasil. (2013). Relatório Final: 3ạ Conferência Nacional dos Direitos da Pessoa com Deficiência. Brasília: SDH/PR - SNPD - Conade.

Bruno, M. M. G. (2006). Educação infantil: saberes e práticas da inclusão. Brasília: MEC- Secretaria de Educação Especial.

Cabral Filho, A. V., Ferreira, G. (2013). Movimentos Sociais e o Protecionismo das Pessoas com deficiência. SER Social, 15(32), 93-116.

Costa, H. (2013). Desafios da inclusão na visão histórico-cultural: uma pesquisa participante. Entrevista Oral [7 nov. 2013]. Palmas. Entrevista concedida a Simone Maria Alves de Lima. 
Crochik, J. A. et al. (2006). Preconceitos e atitudes em relação à educação inclusiva. Psicologia Argumento, 24(46), 55-70.

Góes, M. C. R. (2000). A abordagem microgenética na matriz histórico-cultural: uma perspectiva para o estudo da constituição da subjetividade. Cadernos Cedes, 20(50), 9-25.

Góes, M. C. R. (2004). Desafios da inclusão de alunos especiais: a escolarização do aprendiz e sua constituição como pessoa. In: Góes, M. C. R.; Laplane, A.L. F. (Org). Políticas e práticas de educação inclusiva (pp. 69-92). Campinas: Autores Associados.

Januzzi, G. M. (2006). A educação do deficiente no Brasil: dos primórdios ao inicio do século XXI. Campinas, SP: Autores Associados.

Lanna Júnior, M. C. M. (2010). História do Movimento Político das Pessoas com Deficiência no Brasil. Brasília: Secretaria de Direitos Humanos.

Leontiev, A. (1978). Actividade, Consciência e Personalidade. Tradução de Martin, M. S. C. Recuperado em 5 outubro, 2013, de http://www.livrosgratis.com.br/arquivos_livros/ ma000004.pdf

Lima, S. M. A. (2014). Desafios da inclusão na visão histórico cultural: uma pesquisa participante. Dissertação de Mestrado, Universidade Federal do Tocantins, Palmas, TO, Brasil.

Martins, P. (2013). Desafios da inclusão na visão histórico-cultural: uma pesquisa participante. Entrevista Oral [26 nov. 2013]. Palmas. Entrevista concedida a Simone Maria Alves de Lima.

Neves, A. (2013). Desafios da inclusão na visão histórico-cultural: uma pesquisa participante. Entrevista Oral [13 nov. 2013]. Palmas. Entrevista concedida a Simone Maria Alves de Lima.

Pilatti, F. et al. (2012). Olhares para a educação inclusiva. Joaçaba. Recuperado em 23 agosto, 2013, de http://editora.unoesc.edu.br/index.php/achs/article/viewFile/2137/pdf

Pires, H. (2013). Desafios da inclusão na visão histórico-cultural: uma pesquisa participante. Entrevista Oral [10 dez. 2013]. Palmas. Entrevista concedida a Simone Maria Alves de Lima.

Rolim, C. L. (2014). Cursos de pedagogia: desafios e perspectivas para o ensino de matemática. Unemat, 21(1), 83-98.

Triviños, A. N. S. (1990). A pesquisa qualitativa em educação. São Paulo: Atlas.

Vygotsky, L. S. (1997). Fundamentos de defectologia. Obras escogidas: Vol. 5. Madrid: Visor. 